\title{
Leisure physical activity and various pain symptoms among adolescents
}

Urho M Kujala, Simo Taimela, Tero Viljanen

\begin{abstract}
Objectives-To investigate the association between leisure physical activity and various pain symptoms in adolescents.

Methods-In this nationwide cohort based cross sectional study in Finland, 698 schoolchildren, 344 girls and 354 boys, aged 10 to 17 years responded to $a$ questionnaire on pain symptoms (neck and shoulder pain, upper back pain, low back pain, upper limb pain, lower limb pain, headache, and abdominal pain) and physical activity habits and also participated in a fitness test.

Results-Reported physical activity correlated with measured fitness. Musculoskeletal pains $(p=0.013)$ (in particular low back pain $(p=0.022)$, upper limb pain $(p<0.001)$, and lower limb pain $(p<0.001))$ were found more often in subjects participating in large amounts of leisure physical activity, while non-musculoskeletal pains $(p=0.065)$ (in particular headache among boys $(p=0.004))$ tended to be less common. Co-occurrence of different musculoskeletal pains was common in subjects participating in sports.

Conclusions-In addition to its likely long term health benefits, vigorous physical activity causes musculoskeletal pains during adolescence. This should be considered when tailoring health promotion programmes to adolescents. Also, cooccurrence of musculoskeletal pains may occur as the result of sports activity, which should be considered as a confounder in epidemiological studies on fibromyalgia and related issues.

(Br F Sports Med 1999;33:325-328)
\end{abstract}

Unit for Sports and Exercise Medicine, Institute of Biomedicine, University of Helsinki, Helsinki, Finland U M Kujala $\mathrm{T}$ Viljanen

DBC International, Vantaa, Finland $S$ Taimela

Correspondence to: Dr U M Kujala, Unit for Sports and Exercise Medicine, Mannerheimintie 17 (Töölö Sports Hall), FIN-00250 Helsinki, Finland.

Accepted for publication 3 February 1999
Keywords: physical activity; musculoskeletal pain; adolescence

Leisure physical activity has been recommended to prevent obesity and many chronic diseases of adulthood, and starting physical activity when young probably confers the greatest health benefits. ${ }^{12}$ However, our knowledge of the immediate health risks and benefits of exercise among adolescents is limited. ${ }^{3}$ Moreover, musculoskeletal pain syndromes and disability are major health problems in adults. A better understanding of pain and resulting disabilities in adolescents may provide further clues to the origins of adult problems. ${ }^{4}$ The purpose of our study was to evaluate the occurrence of various pains and their associations with physical activity among Finnish children and adolescents.
Subjects and methods

The subjects of our nationwide cohort based questionnaire survey and field study were pupils of 43 different state schools selected on the basis of cluster sampling. Areas of Finland were included in the sampling process to represent different parts of the country-for example, south/middle/north — and living conditions - for example, urban/rural. The subjects were informed that the main aim of the study was to investigate the physical activity and fitness of Finnish children. The data were collected in late 1993 by a team of six supervisors trained for the purpose. The subjects were 698 children and adolescents: 344 girls and 354 boys. Only subjects in the 4 th grade (10 years), 8th grade (14 years), and 10th grade (16 years) of the selected schools participated. All these children at school during the day of the field survey visit and routinely participating in physical education classes (compulsory for all pupils) filled in a questionnaire and were included in the study. After completing the questionnaire, all subjects participated in a fitness test except for seven, who were prevented from doing so by pains or acute infection. Unfortunately, some of the 10th grade classes had examinations on the study day, which prevented their participation and decreased the number of subjects in our oldest age group. Table 1 presents the numbers in each sex and age category.

The questionnaire asked about the occurrence (No/Yes) of various pains (neck and shoulder pain, upper back pain, low back pain, upper limb pain, lower limb pain, headache, and abdominal pain) that interfered with school work or leisure activities during the preceding 12 months. The low back area was demonstrated with a drawing. We also calculated a sum score for musculoskeletal pain (neck and shoulder pain, upper back pain, low back pain, upper limb pain, lower limb pain; range 0 to 5 points) and non-musculoskeletal pain (headache, abdominal pain; range 0 to 2 points). Questions on pain symptoms were located on a separate page of the questionnaire, and in this association there were no comments on physical activity, which were found on other pages of the questionnaire.

Table 1 Number of subjects by age and gender

\begin{tabular}{lllrl}
\hline \multicolumn{4}{c}{ Age (years) } & \\
\cline { 2 - 4 } & 10 & 14 & 16 & All \\
\hline Boys & 151 & 134 & 69 & 354 \\
Girls & 170 & 126 & 48 & 344 \\
All & 321 & 260 & 117 & 698 \\
\hline
\end{tabular}


Table 2 Reported yearly prevalence of different pain symptoms according to age and gender

\begin{tabular}{|c|c|c|c|c|c|c|}
\hline & \multicolumn{3}{|l|}{ Age (years) } & \multirow[b]{2}{*}{ All } & \multirow{2}{*}{$\begin{array}{l}P \text { for } \\
\text { gender }\end{array}$} & \multirow{2}{*}{$\begin{array}{l}\text { Pfor } \\
\text { age }\end{array}$} \\
\hline & 10 & 14 & 16 & & & \\
\hline \multicolumn{7}{|c|}{ Neck or shoulder pain } \\
\hline Boys & $8.7(13)$ & $22.4(30)$ & $11.6(8)$ & $14.4(51)$ & \multirow{3}{*}{0.0037} & \\
\hline Girls & $15.9(27)$ & $29.4(37)$ & $31.3(15)$ & $23.0(79)$ & & \\
\hline All & $12.5(40)$ & $25.8(67)$ & $19.7(23)$ & $18.6(130)$ & & 0.0002 \\
\hline \multicolumn{7}{|c|}{ Upper back pain } \\
\hline Boys & $9.3(14)$ & $9.7(13)$ & $8.7(6)$ & $9.3(33)$ & \multirow{3}{*}{0.080} & \\
\hline Girls & $3.5(6)$ & $9.5(12)$ & $4.2(2)$ & $5.8(20)$ & & \\
\hline All & $6.2(20)$ & $9.6(25)$ & $6.8(8)$ & $7.6(53)$ & & 0.29 \\
\hline \multicolumn{7}{|c|}{ Low back pain } \\
\hline Boys & $7.9(12)$ & $12.7(17)$ & $11.6(8)$ & $10.5(37)$ & \multirow{3}{*}{0.80} & \\
\hline Girls & $4.1(7)$ & $19.0(24)$ & $14.6(7)$ & $11.0(38)$ & & \\
\hline All & $5.9(19)$ & $15.8(41)$ & $12.8(15)$ & $10.7(75)$ & & 0.0005 \\
\hline \multicolumn{7}{|c|}{ Upper limb pain } \\
\hline Boys & $9.3(14)$ & $7.5(10)$ & $7.3(5)$ & $8.2(29)$ & \multirow{3}{*}{0.16} & \\
\hline Girls & $4.1(7)$ & $7.1(9)$ & $6.3(3)$ & $5.5(19)$ & & \\
\hline All & $6.5(21)$ & $19(7.3)$ & $6.8(8)$ & $6.9(48)$ & & 0.94 \\
\hline \multicolumn{7}{|c|}{ Lower limb pain } \\
\hline Boys & $17.2(26)$ & $24.6(33)$ & $15.9(11)$ & $19.8(70)$ & \multirow{3}{*}{0.62} & \\
\hline Girls & $17.6(30)$ & $18.3(23)$ & $20.8(10)$ & $18.3(63)$ & & \\
\hline All & $17.4(56)$ & $21.5(56)$ & $17.9(21)$ & 19.1 (133) & & 0.43 \\
\hline \multicolumn{7}{|c|}{ Headache } \\
\hline Boys & $33.1(50)$ & $27.6(37)$ & $11.6(8)$ & $26.8(95)$ & \multirow{3}{*}{$<0.0001$} & \\
\hline Girls & $40.6(69)$ & $56.3(71)$ & $39.6(19)$ & $46.2(159)$ & & \\
\hline All & $37.1(119)$ & $41.5(108)$ & $23.1(27)$ & $36.4(254)$ & & 0.0025 \\
\hline \multicolumn{7}{|c|}{ Abdominal pain } \\
\hline Boys & $22.5(34)$ & $17.2(23)$ & $7.3(5)$ & $17.5(62)$ & \multirow{3}{*}{0.0014} & \\
\hline Girls & $24.7(42)$ & $34.1(43)$ & $20.8(10)$ & $27.6(95)$ & & \\
\hline All & $23.7(76)$ & $25.4(66)$ & $12.8(15)$ & $22.5(157)$ & & 0.020 \\
\hline
\end{tabular}

Results are percentages with numbers in parentheses. Statistical analysis was by $\chi^{2}$ test.

Frequency (nine alternatives), intensity (four alternatives), duration (eight alternatives), and mode of habitual physical activity outside school hours were inquired about using structured questions (Appendix). To calculate the volume of activity, we produced an activity metabolic equivalent (MET) index by assigning a multiple of resting metabolic rate (MET score) to each activity and calculating the product of intensity $x$ duration $\times$ frequency of activity. ${ }^{5}$ The leisure activity MET index was expressed as the sum score of leisure MET-hours per week, and the index ranged from 0 to 157 . The level of activity was expressed as low, moderate, or high on the basis of age and sex specific MET index tertiles calculated from the frequency distributions.

To validate the leisure physical activity questionnaire, we tested the fitness of our subjects using the multistage $20 \mathrm{~m}$ shuttle run test. ${ }^{6}$ In this test the subjects run back and forth over a $20 \mathrm{~m}$ indoor course and they adjust their pace according to intermittent sound signals from a pre-recorded tape. The signals gradually speed up, and the subjects do likewise until unable to

Table 3 Summary of the associations between pain symptoms and leisure MET index and the age and sex adjusted means of the MET index for those with pain and without pain, and percentage of subjects with pain in each age and sex specific MET index tertile

\begin{tabular}{|c|c|c|c|c|c|c|c|}
\hline \multirow[b]{2}{*}{ Pain } & \multirow[b]{2}{*}{$F^{\star}$} & \multirow[b]{2}{*}{$p^{\star}$} & \multicolumn{2}{|c|}{$\begin{array}{l}\text { Mean MET } \\
\text { index by paint }\end{array}$} & \multicolumn{3}{|c|}{$\begin{array}{l}\% \text { of subjects with pain } \\
\text { by MET tertile }\end{array}$} \\
\hline & & & Yes & No & Low & Middle & High \\
\hline Neck and shoulder pain & 0.1 & 0.74 & 31.5 & 31.5 & 18.4 & 24.4 & 19.4 \\
\hline Upper back pain & 1.5 & 0.22 & 36.7 & 32.7 & 5.9 & 11.2 & 8.8 \\
\hline Low back pain & 5.3 & 0.022 & 39.1 & 31.0 & 9.7 & 11.7 & 14.6 \\
\hline Upper limb pain & 12.2 & 0.0005 & 52.8 & 31.5 & 1.9 & 9.9 & 12.0 \\
\hline Lower limb pain & 11.9 & 0.0006 & 41.1 & 30.5 & 12.4 & 24.5 & 27.2 \\
\hline \multicolumn{8}{|l|}{ Headache $\ddagger$} \\
\hline Boys & 8.6 & 0.0037 & 29.8 & 42.3 & 35.7 & 32.4 & 19.4 \\
\hline Girls & 0.2 & 0.64 & 25.4 & 26.2 & 50.5 & 45.8 & 51.3 \\
\hline Abdominal pain & 3.1 & 0.077 & 26.5 & 33.6 & 30.3 & 22.4 & 22.0 \\
\hline
\end{tabular}

${ }^{\star}$ By three way analysis of variance.

tBy analysis of covariance; means adjusted for age and sex.

$\ddagger$ Gender-headache interaction, $\mathrm{p}=0.037$. match the pace. The stage number they have reached at this point is used to predict the maximum aerobic power. The shuttle run test result correlated with sex (partial correlation coefficient $r=0.32, \mathrm{p}<0.001)$, age $(r=0.45$, $\mathrm{p}<0.001)$, and the MET index $(r=0.30$, $\mathrm{p}<0.001)$.

STATISTICAL ANALYSIS

We calculated the frequency distributions of different pain symptoms according to age and sex categories as well as MET index tertiles. The distribution of the MET index was skewed to the right in both sexes - that is, high MET index levels were less frequent than low levels (data not shown). Because of the skewed distribution, we applied a base 10 logarithmic transformation to the MET index for parametric statistical calculations. We tested our specific a priori hypotheses that different pain symptoms and leisure physical activity are associated using separate three way analysis of variance computations for each symptom category. Our analysis of variance models controlled for age and gender (between factors), and the statistical differences in physical activity $\left(\log _{10}\right.$ of the MET index as the dependent variable) between those with and without the symptom were calculated. We also calculated the individual sum scores for the musculoskeletal pains (range 0 to 5) and nonmusculoskeletal pains (range 0 to 2). Occurrence of the various pain symptoms with leisure physical activity was tested with a two way analysis of variance model where sex and a tertile based categorical variable of leisure activity were (between) factors and the pain scores were the dependent variables. For hypothesis testing the level of statistical significance was set at $\mathrm{p}<0.05$.

\section{Results}

Neck and shoulder pain, headache, and abdominal pain were more common in girls than boys (table 2). Neck and shoulder pain and low back pain were less common at 10 years than in later adolescence, and headache and abdominal pain were less common at 16 than at 14 (table 2).

In the three way analysis of variance analysing the associations between age, gender, leisure physical activity index, and different pain symptoms, there were no second degree interactions except in the case of headache. High leisure physical activity index was associated with low back pain, upper limb pain, and lower limb pain in both genders, and with less headache among boys (table 3 ). In particular, limb pains were least frequent in the low physical activity index tertile, while in boys the occurrence of headache was low in the high physical activity index tertile (table 3 ).

There were 418 (59.9\%) subjects who had no musculoskeletal pains; the musculoskeletal pain score was 1 in $178(25.5 \%)$ subjects, 2 in $61(8.7 \%), 3$ in $29(4.2 \%), 4$ in eight $(1.1 \%)$, and 5 in four $(0.6 \%)$. There were $402(57.6 \%)$ subjects without non-musculoskeletal pains; the non-musculoskeletal pain score was 1 in $180(25.8 \%)$ subjects, and 2 in $116(16.6 \%)$. 

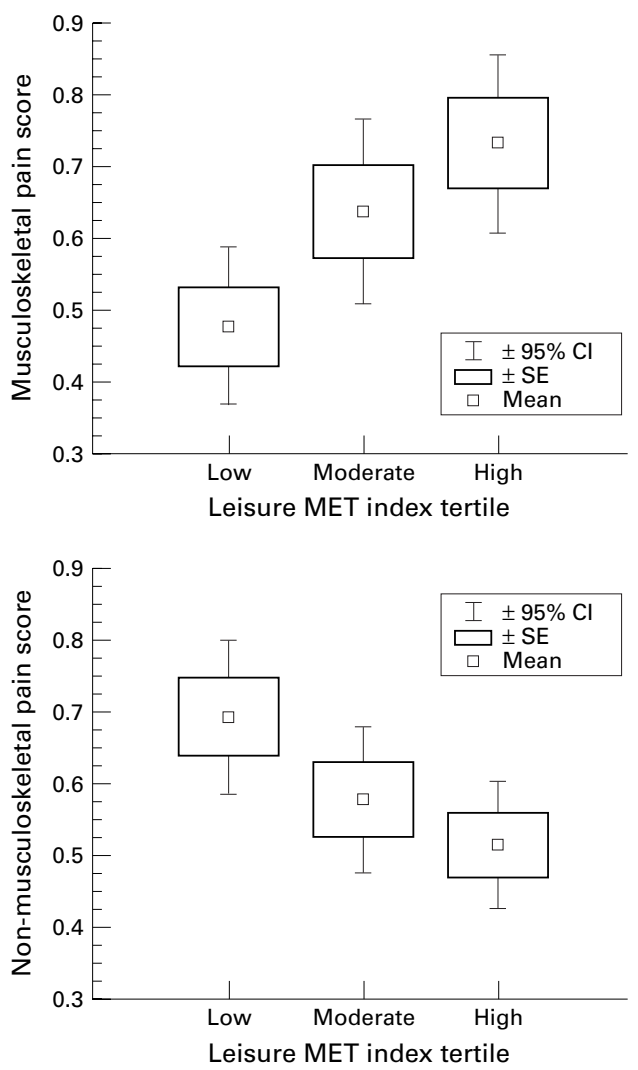

Figure 1 Musculoskeletal and non-musculoskeletal pain scores by leisure MET index tertiles.

Those with a high leisure physical activity MET index had high musculoskeletal pain sum scores $(\mathrm{F}=4.4, \mathrm{p}=0.013)$; no sex difference $(\mathrm{F}=0.25, \mathrm{p}=0.62)$ or interaction $(\mathrm{F}=2.1, \mathrm{p}$ $=0.12$ ) was found. Subjects with a high leisure physical activity MET index tended to have low non-musculoskeletal pain scores $(\mathrm{F}=2.7$, $\mathrm{p}=0.065$ ), but there was a significant sex difference $(F=25.0, p<0.0001)$, girls more frequently reporting co-occurrence of nonmusculoskeletal pains; no significant interaction ( $\mathrm{F}=1.5, \mathrm{p}=0.22$ ) was found (fig 1 ).

Of those reporting being members of at least one sports club, $19.7 \%$ (70 of 356) had a musculoskeletal pain score of at least 2 compared with $9.4 \%$ (32 of 342) of nonmembers ( $\mathrm{p}=0.0001$ by $\chi^{2}$ test); $13.5 \%$ of sports club members (48 of 356) had a non-musculoskeletal pain score of 2 compared with $19.9 \%$ (68 of 342) of non-members ( $p=$ 0.023 by $\chi^{2}$ test). However, high musculoskeletal pain score was associated with high non-musculoskeletal pain score in both boys ( $\mathrm{p}$ $=0.0001$ by $\chi^{2}$ test $)$ and girls $\left(\mathrm{p}=0.0028\right.$ by $\chi^{2}$ test).

\section{Discussion}

Although high physical activity during adolescence improves fitness and may prevent future disease, there are also adverse effects. Sports may cause acute or stress injuries to the developing musculoskeletal system. Our data are consistent with earlier epidemiological findings that sports participation during adolescence is associated with higher occurrence of apophyseal pains. ${ }^{7}$ Not surprisingly, adolescents who participate in sports also have more acute sports injuries. ${ }^{3}$ In agreement with earlier findings ${ }^{89}$ the prevalence of low back pain in our study increased with age from 10 to 16 years. There is also epidemiological evidence that sports injuries during adolescence predispose to back pain and even cause anatomical abnormalities to the growing spine. ${ }^{10}$ Physical activity was not related to neck and shoulder pain in our study. However, high school girls participating in sports involving dynamic use of the upper extremities were shown to have fewer symptoms than those having hobbies involving static postures of the upper limbs or other types of physical activity. ${ }^{11}$ The type and location of musculoskeletal pains are specific for each type of activity.

Our findings concur with earlier observations that headache is more common in girls than boys during adolescence. ${ }^{12}{ }^{13}$ Physical activity may provoke headache by various mechanisms. ${ }^{14}$ Our data are consistent with the finding that headache may be aggravated by physical activity more commonly among girls than boys, ${ }^{15}$ which may explain why an association between high MET index and low occurrence of headache was found only among boys. Although vigorous activity may also cause gastrointestinal disorders, ${ }^{16}$ our study showed that the physically active tend to have less abdominal pains.

Overall, musculoskeletal pains seem to be more common in adolescents who participate in sports. At least a plateau in the intensifying training programmes of young athletes should probably be recommended during the adolescent growth spurt when their skeletal development is at a vulnerable stage. The common occurrence of various musculoskeletal pains among young athletes should also be considered as a possible source of error in studies investigating the development of fibromyalgia and other muscular pains in adolescents, because it is unlikely that these sports related pains are associated with fibromyalgia. In our study, non-musculoskeletal pains tended to be less common in physically active subjects. These pains (headache and abdominal pain) are often considered "psychosomatic" symptoms, which may also be the case in adolescents. Despite the co-occurrence of musculoskeletal and non-musculoskeletal pains, a psychosomatic background is unlikely when musculoskeletal pains are related to high physical activity. Anyway, pain is by definition a subjective phenomenon ${ }^{17}$ and psychogenic pain is difficult to define and recognise. ${ }^{18}$

In summary, in addition to its long term health benefits, vigorous physical activity may cause musculoskeletal pains during adolescence. This should be considered when tailoring health promotion programmes to adolescents. Adolescents usually participate in types of competitive sport that carry an injury risk, such as ball games. Adults more often participate in non-competitive physical activities with lower injury risk, such as walking, jogging, and swimming. Teaching adolescents to participate in non-traumatising physical activities that they could continue as adults is a worthwhile 
challenge because the available research information suggests that the best primary strategy for improving the long term health of children and adolescents through exercise is to create a lifestyle pattern of regular physical activity that may carry over to the adult years, rather than merely to promote childhood physical fitness. ${ }^{1}$

Contributors: $\mathrm{U}$ K initiated and coordinated the formulation of the primary study hypothesis, discussed core ideas, designed the protocol, and participated in data analysis and writing of the paper. S T discussed core ideas and participated in the protocol design, analysis and interpretation of the data, and writing of the paper. T V discussed core ideas, designed the collection of data discussed interpretation of the findings, and contributed to the paper. $\mathrm{U} \mathrm{K}$ is the guarantor.

\section{Appendix}

QUESTIONS ABOUT LEISURE TIME PHYSICAL ACTIVITY (TRANSLATED FROM FINNISH; OUESTIONS 2-4 WERE USED TO CALCULATE MET-HOURS/WEEK)

(1) Do you participate in leisure physical activities (outside school hours)?
(a) Yes
(b) No

(2) How often do you participate in physical activity?
(a) Less than once a month
(b) 1 to 3 times a month
(c) Once a week
(d) Twice a week
(e) 3 times a week
(f) 4 times a week
(g) 5 times a week
(h) 6 times a week
(i) At least 7 times a week

(3) What is the mean duration of your average physical activity session?
(a) Less than $11 \mathrm{~min}$
(b) 11-20 min
(c) 21-30 $\mathrm{min}$
(d) 31-40 $\mathrm{min}$
(e) 41-50 $\mathrm{min}$
(f) $51 \mathrm{~min}$ to 1 hour $10 \mathrm{~min}$
(g) 1 hour $11 \mathrm{~min}$ to 1 hour $30 \mathrm{~min}$
(h) More than 1 hour $30 \mathrm{~min}$

(4) Is your physical activity during leisure time about as tiring (intensive) on average as?
(a) walking (MET value 4)
(b) jogging (MET value 6)
(c) running (MET value 10)
(d) fast running (MET value 13)

(5) List those sports events in which you participate weekly?

During winter:

(1)

(3)

(2)

During summer:

(1)

(3)

$(2)$

(6) Are you a member of a sports club?

(a) No

(b) I am a member of one sports club

(c) I am a member of two sports clubs

(d) I am a member of at least three sports clubs

1 Rowland TW, Freedson PS. Physical activity, fitness, and health in children: a close look. Pediatrics 1994;93:669-72.

2 Department of Health and Human Services. Physical activity and health: a report of the Surgeon General. Atlanta, GA US Department of Health and Human Services, 1996.

3 Aaron DJ, LaPorte RE. Physical activity, adolescence, and health: an epidemiological perspective. Exerc Sports Sci Rev 1997;25:391-405.

4 Mikkelsson M, Salminen JJ, Kautiainen H. Non-specific musculoskeletal pain in preadolescents. Prevalence and 1-year persistence. Pain 1997;73:29-35.

5 Wilson PWF, Paffenbarger RS, Morris JN, et al. Assessment methods for physical activity and physical fitness in population studies: report of a NHLBI workshop. Am Heart $\mathcal{7}$ 1986;111:1177-92.

6 Léger LA, Mercier D, Gadoury C, et al. The multistage 20 metre shuttle run test for aerobic fitness. F Sports Sci 1988; 6:93-101.

7 Kujala UM, Kvist M, Heinonen O. Osgood-Schlatter's disease in adolescent athletes. Retrospective study of incidence and duration. Am 7 Sports Med 1985;13:236-41.

8 Balague F, Dutoit G, Waldburger M. Low back pain in schoolchildren. An epidemiologic study. Scand $\mathcal{F}$ Rehabil Med 1988;20:175-9.

9 Troussier B, Davoine P, de-Gaudemaris R, et al. Back pain in schoolchildren. A study among 1178 pupils. Scand $\mathcal{F}$ Rehabil Med 1994;26:143-6.

10 Kujala UM, Taimela S, Erkintalo M, et al. Low-back pain in adolescent athletes. Med Sci Sports Exerc 1996;28:165-70.

11 Niemi S, Levoska S, Kemilä J, et al. Neck and shoulder symptoms and leisure time activities in high school students. F Orthop Sports Phys Ther 1996;24:25-9.

12 Deubner D. An epidemiologic study of migraine and headache in 10-20 year olds. Headache 1977;1 17:173-80.

13 Linet MS, Stewart WF, Celentano DD, et al. An epidemiologic study of headache among adolescents and adults. fAMA 1989;261:2211-16.

14 Dimeff RJ. Headaches in the athlete. Clin Sports Med 1992; 11:339-49.

15 Wöber-Bingöl C, Wöber C, Wagner-Ennsgraber C, et al. HIS criteria and gender: a study on migraine and tensiontype headache in children and adolescents. Cephalalgia $1996 ; 16: 107-12$

16 Green GA. Gastrointestinal disorders in the athlete. Clin Sports Med 1992;11:453-70.

17 Merskey H, Lindblom U, Mumford JM, et al. Pain terms. A current list with definitions and notes on usage. Pain 1986; 3:S215-21

18 McGrath PJ. Annotation: aspects of pain in children and adolescents. F Child Psychol Psychiatry 1995:36:717-30.

\section{Take home message}

In adolescents, participation in leisure physical activity seems to reduce non-musculoskeletal pain symptoms, but vigorous sport is associated with increased occurrence of musculoskeletal pains. This should be considered when tailoring health promotion programmes using physical activity for growing children.

\section{Commentary}

Although the topic is somewhat "dry", except to educationalists, the authors make recommendations with respect to physical fitness through adult life. It is not a new concept, but the suggestion that children/adolescents should engage in non-competitive and non-aggressive sports from which they are less likely to drop out through injury and which are more likely to achieve a beneficial effect on fitness is given extra weight by the reported incidence of musculoskeletal pain associated with intensive physical activities.

The authors recognise that musculoskeletal pain in children/adolescents who undertake high levels of physical exercise should not be confused with chronic pain syndromes of the fibromyalgia type, and offer a clear warning that this may act as a confounder in epidemiological studies on fibromyalgia. 